\title{
Factors influencing Intention to Purchase Fraudulent Honey among Malaysian Consumers
}

Nur Nisaa Ahmad, Siti Nurhayati Khairatun \& Ungku Fatimah Ungku Zainal Abidin

To Link this Article: http://dx.doi.org/10.6007/IJARBSS/v11-i4/9040

DOI:10.6007/IJARBSS/v11-i4/9040

Received: 05 February 2021, Revised: 10 March 2021, Accepted: 23 March 2021

Published Online: 08 April 2021

In-Text Citation: (Ahmad et al., 2021)

To Cite this Article: Ahmad, N. N., Khairatun, S. N., \& Abidin, U. F. U. Z. (2021). Factors influencing Intention to Purchase Fraudulent Honey among Malaysian Consumers. International Journal of Academic Research in Business and Social Sciences, 11(4), 134-149.

Copyright: (c) 2021 The Author(s)

Published by Human Resource Management Academic Research Society (www.hrmars.com)

This article is published under the Creative Commons Attribution (CC BY 4.0) license. Anyone may reproduce, distribute, translate and create derivative works of this article (for both commercial and non-commercial purposes), subject to full attribution to the original publication and authors. The full terms of this license may be seen at: http://creativecommons.org/licences/by/4.0/legalcode

Vol. 11, No. 4, 2021, Pg. 134 - 149

Full Terms \& Conditions of access and use can be found at http://hrmars.com/index.php/pages/detail/publication-ethics 


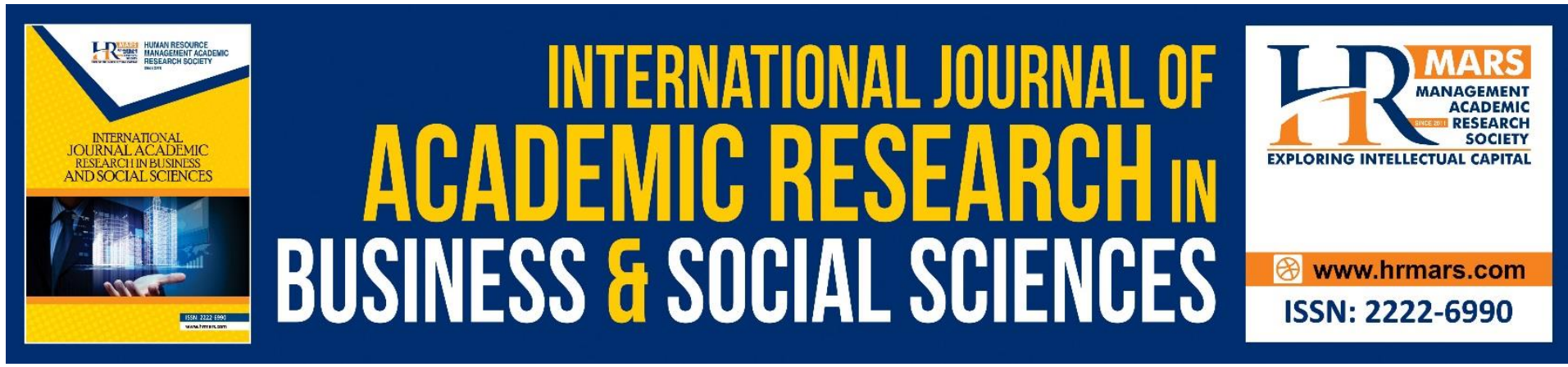

\title{
Factors influencing Intention to Purchase Fraudulent Honey among Malaysian Consumers
}

\section{Nur Nisaa Ahmad ${ }^{1}$, Siti Nurhayati Khairatun ${ }^{2}$ \& Ungku Fatimah Ungku Zainal Abidin²}

${ }^{1}$ Faculty of Food Science and Technology, Universiti Putra Malaysia, 43400 UPM Serdang, Selangor, Malaysia, ${ }^{2}$ Department of Food Service \& Management, Faculty of Food Science and Technology, Universiti Putra Malaysia, 43400 UPM Serdang, Selangor, Malaysia.

Email: snkhairatun@upm.edu.my

\begin{abstract}
This paper aims to assess consumer awareness about fraudulent honey and its impact on purchase intention using an extended Theory of Planned Behaviour model. An online questionnaire survey was administered among honey consumers in Malaysia. Multiple regression analysis was employed on the 289-obtained-data to generate the relationship between awareness, attitude, subjective norms, perceived behavioural control, and consumers' intention to purchase fraudulent honey. Findings show that attitude and perceived behavioural control have a significant and positive relationship with the intention to purchase fraudulent honey. Consumers' unfavourable attitude towards fraudulent honey diminishes their intention to purchase it. Whereas, even with high perceived behavioural control, consumers decide to purchase fraudulent honey because it fulfils their needs. Consumers are aware of fraudulent honey and choose to buy it since it is cheaper and readily available. This study's practical implication is for marketers and policymakers to develop programs or create proper channels to educate consumers in making wise purchasing decisions. Ultimately, consumers have the right to make their own decision.
\end{abstract}

Keywords: Awareness, Consumer Education, Consumer Protection, Honey Fraud, Theory of Planned Behaviour, Food Quality

\section{Introduction}

Food fraud is now becoming a topic of interest in food safety, mainly due to the potential health threat it could harbour. Although food fraud has long existed, the complex nature and length of the supply chain made food fraud an emerging global threat with a larger scale and geographical coverage. Food fraud is riskier than conventional food safety negligence as the adulterants are unconventional, motives are deliberate, and acts are intentional, which are designed to avoid detection. The global food industry suffered an estimated cost of US\$30 to US\$40 billion yearly from food fraud (PWC, 2017).

In a report commissioned by the Department of Homeland Security, food fraud is defined as a "collective term that encompasses the deliberate substitution, addition, tampering or misrepresentation of food, food ingredients or food packaging, or false or 
misleading statements made about a product for economic gain." In a simpler term, it is the deliberate act of modification on food or food packaging, usually for financial gain.

This study explores the topic of food fraud using honey as the context. Honey has had a long history in the sphere of food fraud. It is prone to adulteration due to its high commercial value. It is priced higher than other sweeteners due to its high nutritional values and unique flavour characteristics (Oroian et al., 2018). Honey has been identified statistically, from an extensive record of scholarly journals and media reports, as one of the most adulterated ingredients. It has a long history of dilution, substitution, misrepresentation of floral source and geographical origin (Moore et al., 2012). In Malaysia, a study conducted by Universiti of Malaya Honey Research Laboratory has analysed 40 honey samples obtained from local beekeepers, honey hunters and dealers and concluded that 31 of the honey samples (77\%) are either adulterated honey or synthetic honey made from high fructose syrup (Kamaruddin et al., 2006).

\section{Problem Statement}

Gullible consumers create convenient targets for motivated offenders to take advantage of. Ignorance in consumers leads to poor buying practices. Thus, knowledge contributes to good decision-making. However, it can only impact a person's action or behaviour through the state of awareness of its importance. Oxford dictionary coined awareness as (1) knowledge or perception of a situation or fact (2) concern about and well-informed interest in a particular situation or development. Cambridge dictionary coined awareness as (1) knowledge that something exists, or understanding of a situation or subject at present based on information or experience (2) knowledge and understanding of a particular activity, subject, etc. MerriamWebster dictionary coined awareness as (1) the quality or state of being aware of (2) knowledge and understanding that something is happening or exists. Hence, to put into perspective, consumer awareness is the state of consciousness about a particular subject.

Our central thesis is that awareness influences the consumers' purchase intention, which later dictates their purchasing decision. Ideally, increasing awareness about honey fraud would minimise the purchase of fraudulent honey, hence encouraging fair competition among traders and eventually reducing the supply of fraudulent honey. The growing power of consumers voice has the potential of dictating companies' ways of doing business.

There is a lack of studies on the level of awareness about honey fraud among consumers. Most scientific studies report the prevalence of honey adulteration and focus on the latest most advanced honey authenticity detection method (Fakhlaei et al., 2020; Se et al., 2019; Soares et al., 2017). From a commercial standpoint, there is an abundance of studies assessing consumers' honey preferences and honey's criteria affecting their purchase decision (Batt \& Liu, 2012; Blanc et al., 2021; Kallas et al., 2019; Murphy et al., 2000). However, little is known about consumers' understanding and awareness about the issue of fraudulent honey, as such, insight on the level of consumer awareness about fraudulent honey and the effect of awareness on their intention to purchase fraudulent honey warrant further investigation.

This study aims to assess Malaysian consumer awareness about fraudulent honey and investigate how awareness influences purchase intention towards buying fraudulent honey. Essentially, this study would like to evaluate whether consumers are aware of the prevalence of fraudulent honey and whether there is a correlation between awareness and purchase intention. Apart from that, other factors related to purchase intention will also be examined to enhance the predictability of the research model. Specific objectives of the study are: 
$\boldsymbol{R O}_{1}$ : To determine the level of consumer awareness about fraudulent honey.

$\boldsymbol{R O}_{\mathbf{2}}$ : To examine the influence of consumer awareness on the intention to purchase fraudulent honey.

$\mathbf{R O}_{3} \quad$ : To investigate other factors influencing consumers' purchase intention.

\section{Significance of the Study}

Beyond the financial cost, food fraud can potentially lead to serious public health risks, damage brands' reputation, and ultimately weakens the public trust in authority (PWC, 2017). In the past, big players had an upper hand in dictating consumers' decision because of the restricted communication channel. However, with the world becoming more virtual and borderless, modern consumers are more vocal in wanting more transparency in their purchases. Consumer's voice is seen to be making a presence in the industry. Marketing has shifted tremendously in accommodating to consumers' demand for honesty and ethical products. More and more brands are using marketing strategy such as organic, fair trade and green products to promote an image of good business ethics and integrity.

This study's outcome can be used as a knowledge base for policymakers and the trade association in regulating the food industry's sustainability and integrity. A continuous joint effort between authority, trade association and consumer organisation are deemed necessary and significant to increase public awareness about food fraud. The consumer outreach program is seeming to be the best way to educate the public about food fraud. Accurate dissemination of information about food quality via consumers outreach programs will empower consumers to make a good purchasing decision. Indirectly, this will enhance consumer protection by driving food companies to take proactive measures in safeguarding food quality and information integrity.

\section{Literature Review}

\section{Awareness}

Several studies about consumers' awareness of food adulteration concluded that awareness level is generally low (Gupta \& Panchal, 2009: Ishwar et al., 2016; Nasreen \& Ahmed, 2014; Rekha \& Paul, 2018). Hence, going back to our first research objective, the below hypothesis is formulated:

\section{$\boldsymbol{H}_{1}$ : Awareness about fraudulent honey is low among Malaysian consumers.}

So, how does awareness fit into the intention-behavior paradigm?

In a green products case study, Yadav and Pathak (2017) found consumer attitude and willingness to pay for the premium price are enhanced through increased awareness and proper communication about the benefit of the product. Bashir (2019) studied halal awareness and concluded that awareness has a significant and positive influence on foreign consumers' purchase intention towards halal food products. One plausible reason for the relationship between awareness and purchase intention is that consumers who are well educated or know about halal will favour purchasing halal food products. The availability of halal food products also causes consumers to become more aware of it, which later increases their purchase intention. Azam (2016) concurred that awareness has a significant and positive relationship with the intention to purchase halal food products manufactured by non-Muslim. Hence, the below hypothesis is generated to study the construct of consumer awareness and the intention to purchase. 
$\boldsymbol{H}_{2}$ : There is a negative relationship between consumer awareness about honey fraud and their intention to purchase the fraudulent honey.

\section{Theoretical Framework - Theory in Support of Intention to Purchase}

Theory of Reasoned Action (TRA) is a commonly referred social behaviour model in understanding complex behaviour dynamics and is used across various disciplines in social science studies (Fishbein, 1980). TRA suggests that the performance of a behaviour is influenced by the individual's intention to perform the act. Intention measures the likelihood or amount of effort they are willing to engage in performing the act. There are two factors influencing intention: attitude (individual influence) and subjective norm (normative influence). Intention is a direct predictor of behaviour, which denotes that despite unfavourable attitudes and subjective norm, a person's high intention will still lead to the performance of the behaviour or act.

TRA intends to explain rational behaviours over which a person has complete control. Theory of Planned Behaviour (TPB) was then proposed to include acts not under complete volitional control by adding a new construct, which is the perceived behavioural control (PBC) (Ajzen, 1991). PBC can directly predict behaviour and indirectly predict behaviour through intention. A positive attitude with a favourable subjective norm and a high PBC leads to the likelihood of performing the behaviour. On another note, despite the high intention to engage the behaviour, the action is not likely to happen when PBC is low, indicating that decisions are out of the individual's direct control.

TPB has been applied widely and successfully in many studies as a theoretical framework from which to examine the purchase intention in halal food consumption (Amalia et al., 2020; Lim at al., 2020; Marmaya at al., 2019), organic food consumption (James et al., 2019; Mohammed, 2020; Teng \& Wang, 2015), functional food consumption (Xin \& Seo, 2019), genetically modified food consumption (Rabbanee et al., 2020; Zheng et al., 2017; Zhu et al., 2018), green food consumption (Amin \& Tarun, 2020), ethnic food consumption (Ahmad et al., 2019) and counterfeit products (Fernandes, 2013). Hence, the TPB model is deemed suitable as the theoretical foundation for this research to understand honey buyers' purchase intention.

\section{Conceptual Framework and Hypotheses Development Attitude}

Attitude denotes an individual's evaluation of specific behaviour, whether it makes a positive or negative contribution to his or her life. Consumer's negative evaluation of fraudulent honey prompts low intention to purchase. Hence, the below hypothesis is proposed:

$\boldsymbol{H}_{3}$ : There is a positive relationship between consumer attitude about honey fraud and their intention to purchase fraudulent honey.

\section{Subjective norm}

Subjective norm denotes an individual's perception about others around him or her who think he or she should engage in the behaviour or acceptable to them. In a simple term, it is the perceived social pressure. Negative opinions of fraudulent honey from groups or people who are important to the consumer prompts low intention to purchase it. Thus, the below hypothesis is suggested:

$\boldsymbol{H}_{4}$ : There is a positive relationship between the subjective norm about honey fraud and consumers' intention to purchase fraudulent honey. 


\section{Perceived behavioral control}

PBC refers to an individual's belief that performance of the behaviour is within his or her control or ability, and they have the necessary resources and opportunities to perform the behaviour. Determining the quality of honey might not be within a consumer's direct control since honey adulteration cannot be assessed superficially without lab testing. In contrast, misrepresentation or mislabelling of honey is intended to keep consumers in the dark. Hence, the below hypothesis is developed.

$\boldsymbol{H}_{5}$ : There is a negative relationship between perceived behavioural control and consumers' intention to purchase fraudulent honey.

Thus, this study attempts to address the following research questions with these respective hypotheses:

$\boldsymbol{R O}_{1}$ : To determine the level of consumer awareness about fraudulent honey.

$\boldsymbol{R Q}_{\mathbf{1}}$ : What is the level of awareness about fraudulent honey among Malaysian consumers?

$H_{1}$ : Awareness about fraudulent honey is low among Malaysian consumers.

$\mathbf{R O}_{\mathbf{2}}$ : To examine the influence of consumer awareness on the intention to purchase fraudulent honey.

$\boldsymbol{R Q}_{\mathbf{2}}$ : What is the relationship between consumer awareness and their intention to purchase fraudulent honey?

$\boldsymbol{H}_{\mathbf{2}}$ : There is a negative relationship between consumer awareness about honey fraud and their intention to purchase the fraudulent honey.

$\boldsymbol{R O}_{3}$ : To investigate other factors influencing consumers' purchase intention.

Based on Theory of Planned Behavior, the following hypotheses can be formulated:

$\boldsymbol{H}_{3} \quad$ : There is a positive relationship between consumer attitude about honey fraud and their intention to purchase fraudulent honey.

$\boldsymbol{H}_{4} \quad$ : There is a positive relationship between the subjective norm about honey fraud and consumers' intention to purchase fraudulent honey.

$\boldsymbol{H}_{5} \quad$ : There is a negative relationship between perceived behavioural control and consumers' intention to purchase fraudulent honey. 


\section{Research framework}

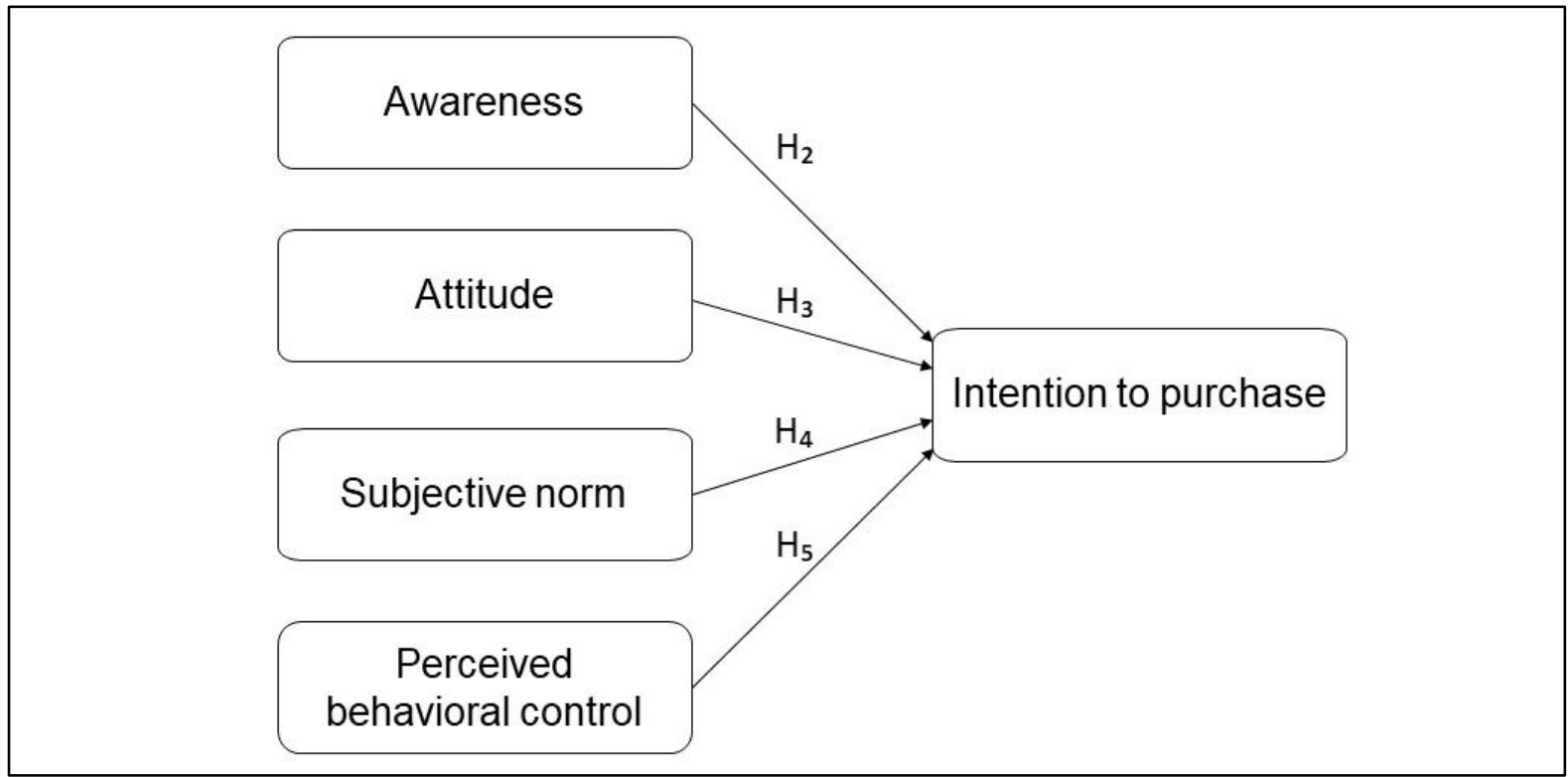

Figure 1. The research framework of factors influencing the intention to purchase fraudulent honey

\section{Methodology}

The population analysed in this study consisted of Malaysian honey consumers residing in Malaysia. An online survey questionnaire was developed and distributed through a network of acquaintances to determine the level of awareness about fraudulent honey and evaluate the relationship between consumer awareness and the intention to purchase fraudulent honey. The data were collected from December 2020 till January 2021. An invitation containing the questionnaire's link was emailed to a large pool of email addresses, including colleagues and personal contacts and email contacts collected through Universiti Putra Malaysia's graduate student database. The respondents were also requested to forward it to their connections to reach a larger demographic of people. Thus, the snowballing technique was used in this study.

The first question identifies potential respondents fitting to the study by filtering respondents into honey consumers and non-honey consumers. Consumers who have not consumed honey within the past 12 months are classified as non-honey consumers. They were excluded out from the study. On the other hand, consumers who acknowledged consuming honey within the past 12 months were selected and further prompted with subsequent questions relating to their honey consumption pattern and purchasing frequency, as tabulated in Table 2.

The questionnaire consisted of three sections. Section 1 involves questions on factors influencing the intention to purchase fraudulent honey. The four independent variables measured are consumer awareness, attitude, subjective norm, and perceived behavioural control. Section 2 involves questions on the intention to purchase fraudulent honey. Section 3 involves questions on the demographic background.

For the awareness construct, using a 5-point Likert scale with "1" being "not at all aware" to "5" being "extremely aware", seven items were adopted from other studies on consumer awareness (Azam, 2016; Ghansah et al., 2021). The items were constructed using the same pattern as the other studies, which prompts consumer awareness about the objective knowledge of the subject matter. 
A 5-point Likert scale with 1 being "strongly disagree" and 5 being "strongly agree" was used to measure the constructs of attitude, subjective norm, perceived behavioral control and purchase intention. For attitude construct, four items were adopted to measure the degree to which buying fraudulent honey is a desirable, wise, healthy, and favourable choice (Dangi et al., 2020; Wang et al., 2020; Zhou et al., 2013). For the subjective norm construct, four items were adopted to measure the degree of influence on the respondent's perception of others around him or her thinks about fraudulent honey. Each item measured a specific circle of people important to the respondents, which are family, friends, colleagues, and those whose opinion matters to the respondent (Dangi et al., 2020). For the perceived behavioral control construct, three items were adopted to measure the degree of ability of the individual to perform a behaviour (Dangi et al., 2020; Jin Ma, Littrell \& Niehm, 2012; Zhou et al., 2013). For the purchase intention construct, three items were adopted to measure the willingness or readiness of purchasing fraudulent honey (Dangi et al., 2020; Jin Ma et al., 2012; Xin \& Seo, 2019).

\section{Results and Discussion}

Demographic Profiling

A total of 473 responses were collected from the online survey; 396 data were usable, with 77 data being invalid because it did not fall under the criteria of the sampling unit, which is Malaysian consumers. The 396 data were considered for analysis. $73 \%$ of the respondents (289 data) were filtered as honey consumers. $27 \%$ of the respondents (107 data) falls under non-honey consumers since they had not consumed honey within the last 12 months. The demographic background of the honey consumers is as Table 1.

Table 1. Socio-demographic statistics of respondents

\begin{tabular}{lll}
\hline & \multicolumn{2}{c}{ Honey consumers $(\mathrm{n}=289)$} \\
Demographic Variable & Frequency & Percentage \\
\hline Age & & \\
20 and below & 1 & $0.35 \%$ \\
$21-30$ & 126 & $43.60 \%$ \\
$31-40$ & 102 & $35.29 \%$ \\
$41-50$ & 38 & $13.15 \%$ \\
51 and above & 22 & $7.61 \%$ \\
& & \\
\hline Gender & & \\
Female & 203 & $70.24 \%$ \\
Male & 86 & $29.76 \%$ \\
& & \\
\hline Ethnicity & & \\
Malay & 212 & $73.36 \%$ \\
Chinese & 39 & $13.49 \%$ \\
Indian & 28 & $9.69 \%$ \\
Bumiputera (Sabah/Sarawak) & 9 & $3.11 \%$ \\
\hline
\end{tabular}




\begin{tabular}{|c|c|c|}
\hline \multicolumn{3}{|l|}{ Current location } \\
\hline Central region (Selangor, Putrajaya, Kuala Lumpur) & 185 & $64.01 \%$ \\
\hline Southern region (Negeri Sembilan, Melaka, Johor) & 37 & $12.80 \%$ \\
\hline East coast region (Pahang, Terengganu, Kelantan) & 25 & $8.65 \%$ \\
\hline Northern region (Perlis, Kedah, Penang, Perak) & 27 & $9.34 \%$ \\
\hline Sabah and Sarawak & 15 & $5.19 \%$ \\
\hline \multicolumn{3}{|l|}{ Highest education level } \\
\hline No formal education & 0 & $0.00 \%$ \\
\hline Secondary school & 10 & $3.46 \%$ \\
\hline Diploma/ Certificate & 22 & $7.61 \%$ \\
\hline Bachelor's degree & 114 & $39.45 \%$ \\
\hline Master's/ PhD & 139 & $48.10 \%$ \\
\hline Professional & 2 & $0.69 \%$ \\
\hline Rather not tell & 2 & $0.69 \%$ \\
\hline \multicolumn{3}{|l|}{ Occupation } \\
\hline Government sector & 59 & $20.42 \%$ \\
\hline Private sector & 83 & $28.72 \%$ \\
\hline Self-employed & 34 & $11.76 \%$ \\
\hline Unemployed & 8 & $2.77 \%$ \\
\hline Student & 96 & $33.22 \%$ \\
\hline Retiree & 9 & $3.11 \%$ \\
\hline \multicolumn{3}{|l|}{ Monthly household income } \\
\hline Less than MYR 2,000 & 72 & $24.91 \%$ \\
\hline MYR 2,000 - MYR 4,999 & 82 & $28.37 \%$ \\
\hline MYR 5,000 - MYR 7,999 & 53 & $18.34 \%$ \\
\hline MYR 8,000 - MYR10,999 & 34 & $11.76 \%$ \\
\hline MYR 11,000 - MYR 13,999 & 17 & $5.88 \%$ \\
\hline MYR 14,000 and more & 31 & $10.73 \%$ \\
\hline
\end{tabular}

Table 2. Consumption and purchasing behavior for honey consumers

\begin{tabular}{lll}
\hline & Frequency & Percentage \\
\hline Reason for purchasing honey $(\mathrm{n}=289)$ & & \\
\hline For consumption because I love the taste & 232 & $80.28 \%$ \\
\hline For consumption as a replacer for sugar & 137 & $47.40 \%$ \\
\hline For consumption due to its health benefits & 270 & $93.43 \%$ \\
\hline For cooking and baking use & 180 & $62.28 \%$ \\
\hline For beauty or cosmetic external use & 90 & $31.14 \%$ \\
\hline & & \\
\hline Yearly expenditure on honey ( $n=289)$ & & \\
\hline Less than MYR 50 & 82 & $28.37 \%$ \\
\hline Between MYR 50- MYR 199 & 144 & $49.83 \%$
\end{tabular}


INTERNATIONAL JOURNAL OF ACADEMIC RESEARCH IN BUSINESS AND SOCIAL SCIENCES Vol. 11, No. 4, 2021, E-ISSN: 2222-6990 @ 2021 HRMARS

\begin{tabular}{|c|c|c|}
\hline Between MYR 200- MYR 350 & 34 & $11.76 \%$ \\
\hline Above MYR 350 & 29 & $10.03 \%$ \\
\hline \multicolumn{3}{|c|}{ Number of times of honey products purchased yearly $(n=289)$} \\
\hline Less than 5 times & 232 & $80.28 \%$ \\
\hline Between 5-9 times & 43 & $14.88 \%$ \\
\hline Between 10-14 times & 8 & $2.77 \%$ \\
\hline 15 times and more & 6 & $2.08 \%$ \\
\hline \multicolumn{3}{|c|}{ Frequency of buying honey from following shops } \\
\hline \multicolumn{3}{|c|}{ Supermarkets (e.g. Giant, Tesco, AEON, Mydin) $(n=289)$} \\
\hline Never & 98 & $33.91 \%$ \\
\hline Sometimes & 134 & $46.37 \%$ \\
\hline Always & 57 & $19.72 \%$ \\
\hline \multicolumn{3}{|c|}{ Convenience stores (e.g. 99 Speedmart, KK mart, 7-eleven) ( $n=289)$} \\
\hline Never & 210 & $72.66 \%$ \\
\hline Sometimes & 70 & $24.22 \%$ \\
\hline Always & 9 & $3.11 \%$ \\
\hline \multicolumn{3}{|c|}{ Pharmacies (e.g. Watson, Guardian, AEON Wellness) $(n=289)$} \\
\hline Never & 190 & $65.74 \%$ \\
\hline Sometimes & 83 & $28.72 \%$ \\
\hline Always & 16 & $5.54 \%$ \\
\hline \multicolumn{3}{|c|}{ Specialty health stores (e.g. BMS organics, Justlife, NHF) $(n=289)$} \\
\hline Never & 165 & $57.09 \%$ \\
\hline Sometimes & 93 & $32.18 \%$ \\
\hline Always & 31 & $10.73 \%$ \\
\hline \multicolumn{3}{|l|}{ Honey shops $(n=289)$} \\
\hline Never & 134 & $46.37 \%$ \\
\hline Sometimes & 108 & $37.37 \%$ \\
\hline Always & 47 & $16.26 \%$ \\
\hline \multicolumn{3}{|c|}{ Bee farms (Local beekeepers) $(n=289)$} \\
\hline Never & 142 & $49.13 \%$ \\
\hline Sometimes & 93 & $32.18 \%$ \\
\hline Always & 54 & $18.69 \%$ \\
\hline \multicolumn{3}{|c|}{ Local honey hunters (e.g. Orang asli in Cameron Highland) ( $n=289)$} \\
\hline Never & 142 & $49.13 \%$ \\
\hline Sometimes & 92 & $31.83 \%$ \\
\hline Always & 55 & $19.03 \%$ \\
\hline
\end{tabular}




\section{Descriptive Statistic}

The first objective is to assess the level of consumer awareness about fraudulent honey among Malaysians. Using a 5-point Likert scale, ranging from "1" being "not at all aware" to " 5 " being "extremely aware", finding shows that on average, consumers are highly aware of the topic of fraudulent honey $(M=4.10)$ and that fraudulent honey involves the mixing with sugar $(M=4.55)$. They are moderately aware of the presence of fraudulent honey sold on the market $(M=3.59)$, the safety issues or concerns related to fraudulent honey $(M=3.64)$, and that it involves mixing with low-quality honey $(M=3.95)$. Whereas, they are slightly aware that fraudulent honey involves incorrect labelling of country of origin $(M=2.96)$ and incorrect labelling of floral source $(M=2.85)$.

\section{Reliability Analysis}

The reliability of each construct was assessed using Cronbach's Alpha to test each item's consistency in measuring its respective construct. A value of 0.7 or higher is generally considered high reliability (Hair et al., 2010; Pallant, 2016). As shown in Table 3, each construct has a Cronbach's alpha of greater than 0.7.

Table 3. Reliability analysis of study constructs

\begin{tabular}{lcc}
\hline Constructs & Number of items & Cronbach's alpha \\
\hline Consumer awareness & 7 & .840 \\
Attitude & 4 & .851 \\
Subjective norm & 4 & .905 \\
Perceived behavioural control & 3 & .803 \\
Purchase intention & 3 & .935 \\
\hline
\end{tabular}

\section{Multiple Linear Regression}

This study's second objective was to explore the influence of consumer awareness and the factors in the TPB model on Malaysian honey consumers' intention to purchase fraudulent honey. The findings showed that the modified TPB model could explain $28.3 \%$ of the variance in the intention to purchase fraudulent honey. The model was statistically significant, and the findings of this study also demonstrated the strength of TPB in explaining intention to purchase fraudulent honey.

The analysis of intention to purchase fraudulent honey was significant $\left(F_{4,284}=\right.$ 28.035, $\rho=.000)$. Measured variables contributed approximately $28.3 \%\left(R^{2}=.283\right)$ to consumers' intention to purchase fraudulent honey.

Multiple regression was used to estimate the linear equation's coefficients involving the four factors that best predict the model.

A regression equation was generated:

Purchase intention $=-.076+.062$ (awareness) +.534 (attitude) +.076 (subjective norms) + .098 (perceived behavioural control)

Results indicated 'attitude' $(\beta=.080, \rho=.000)$ has the highest effect on intention to purchase fraudulent honey, and it followed by perceived behavioural control $(\beta=.036$, $\rho=.007)$. 'Subjective norm' $(\beta=.061, \rho=.217)$ and 'awareness' $(\beta=.044, \rho=.159)$ have no significant effect on intention to purchase fraudulent honey. 


\section{Discussion}

The study shows that attitude has a significant and positive relationship with intention to purchase fraudulent honey. Those with high unfavourable attitudes about honey fraud appeared to have low intention to purchase fraudulent honey. This result is in line with many recent findings that show attitude is a strong significant predictor in different food consumption intention such as in halal food consumption (Bashir, 2019; Shah Alam \& Mohamed Sayuti, 2011), green food consumption (Amin et al., 2020) and organic food consumption (Saleki et al., 2019).

The result shows that perceived behavioural control has a significant and positive relationship with purchase intention. This finding is in line with the results by Ali, Xiaoling et al. (2018), Chung, Stoel et al. (2012), Jin Ma et al. (2012) and Saleki et al. (2019), which showed that PBC could significantly predict consumption intention. The higher an individual's capacity to distinguish honey's quality and purity, the higher the intention to purchase fraudulent honey. One plausible explanation for this finding could be that fraudulent honey does fulfil consumers' consumption needs. Consumers purchase fraudulent honey because it is cheaper and readily available, hence more convenient to purchase.

Subjective norm was non-significantly related to purchase intention. This finding is contrary to previous research by Chung et al. (2012), Mohammed (2020) and Shah Alam and Mohamed Sayuti (2011), which found that subjective norm is a significant predictor in behavioural decisions, especially in Asian culture as opposed to individualistic cultures in western countries. They concluded that in collectivistic culture such as Asian countries, people tend to strive for in-group rather than personal goals.

The result shows that awareness does not have a significant effect on purchase intention. This finding is contrary to other studies by Azam (2016) on halal food products packaged by non-Muslim manufacturers, Hassan et al. (2020) on functional food, Zheng et al. (2017) on genetically modified foods, in which all of them concluded awareness as a significant predictor of purchase intention. One plausible explanation for this result could be that intention to purchase fraudulent honey is not affected by awareness level. A high level of awareness does not subdue the intention to purchase fraudulent honey. To put it simply, consumers do not care. The result shows that consumers are indeed aware of the prevalence of fraudulent honey but still choose to buy it because it fulfils consumers' needs.

\section{Conclusion}

The assumption was that Malaysian honey consumers are not aware of fraudulent honey. Hence, this study was geared towards looking at the awareness level and examining its potential relationship with the intention to purchase fraudulent honey. The finding shows that Malaysian honey consumers are indeed aware of the existence and prevalence of fraudulent honey. Interestingly, the relationship between awareness and purchase intention is non-significant. Even if consumers have high awareness about honey fraud, their purchase intention are not affected by it.

From the proposed research framework, attitude and perceived behavioural control are the two significant predictors of purchase intention. An unfavourable attitude on fraudulent honey diminishes consumers' purchase intention. On an interesting note, perceived behavioural control has a positive relationship with the intention to purchase fraudulent honey. One plausible explanation for the finding is that fraudulent honey does fulfil consumers' needs in being cheaper and conveniently available. Consumers are aware of the honey being adulterated but still choose to buy it. On the other end, the relationship 
between subjective norm and purchase intention is non-significant. The intention to purchase fraudulent honey is majorly influenced by personal interest rather than social preference.

This study contributes to understanding the predictability of the extended TPB model on the intention to purchase fraudulent honey. Attitude is the strongest predictor of intention. This research revealed that consumers who have a negative evaluation of fraudulent honey are more likely to resist the intention to purchase it. It was also found that perceived behavioural control has a significant role in shaping consumer intention to purchase fraudulent honey. At times, consumers consciously decide on buying fraudulent honey because it fulfils their needs of being cheaper and accessible. Thus, marketers and policymakers could develop programs or create proper channels to educate consumers to make wise purchasing decisions. Ultimately, consumers have the right to make their own decision.

The limitations of this study are associated with the use of convenient sampling of honey consumers around Malaysia. Hence, its generalizability to the entire population cannot be made. Further research can be done to obtain a better representation of the whole population by having equal distribution of respondents in each state of Malaysia. Secondly, future studies may expand this study's scope and examine the factors influencing attitudes toward fraudulent honey. This may facilitate a better understanding of the link between attitude and purchase intention.

\section{References}

Ahmad, M. S., Jamil, A., Latif, K. F., Ramayah, T., Ai Leen, J. Y., Memon, M., \& Ullah, R. (2019). Using food choice motives to model Pakistani ethnic food purchase intention among tourists. British Food Journal, 122(6), 1731-1753. https://doi.org/10.1108/BFJ-012019-0024

Ajzen, I. (1991). The theory of planned behaviour. Organisational Behaviour and Human Decision Processes, 50(2), 179-211. https://doi.org/10.1016/0749-5978(91)90020-T

Ali, A., Xiaoling, G., Sherwani, M., \& Hussain, S. (2018). Expanding the theory of planned behaviour to predict Chinese Muslims halal meat purchase intention. British Food Journal, 120(1), 2-17. https://doi.org/10.1108/BFJ-05-2017-0278

Amalia, F. A., Sosianika, A., \& Suhartanto, D. (2020). Indonesian Millennials' Halal food purchasing: merely a habit? British Food Journal, 122(4), 1185-1198. https://doi.org/10.1108/BFJ-10-2019-0748

Amin, S., \& Tarun, M. T. (2020). Effect of consumption values on customers' green purchase intention: a mediating role of green trust. Social Responsibility Journal. https://doi.org/10.1108/SRJ-05-2020-0191

Azam, A. (2016). An empirical study on non-Muslim's packaged halal food manufacturers: Saudi Arabian consumers' purchase intention. Journal of Islamic Marketing, 7(4), 441460. https://doi.org/10.1108/JIMA-12-2014-0084

Bashir, A. M. (2019). Effect of halal awareness, halal logo and attitude on foreign consumers' purchase intention. British Food Journal, 121(9), 1998-2015. https://doi.org/10.1108/BFJ-01-2019-0011

Batt, P. J., \& Liu, A. (2012). Consumer behaviour towards honey products in Western Australia. British Food Journal, 114(2), 285-297. https://doi.org/10.1108/00070701211202449

Blanc, S., Zanchini, R., Di Vita, G., \& Brun, F. (2021). The role of intrinsic and extrinsic characteristics of honey for Italian millennial consumers. British Food Journal. https://doi.org/10.1108/BFJ-07-2020-0622 
Chung, J., Stoel, L., Xu, Y., \& Ren, J. (2012). Predicting Chinese consumers' purchase intentions for imported soy-based dietary supplements. British Food Journal, 114(1), 143-161. https://doi.org/10.1108/00070701211197419

Dangi, N., Narula, S. A., \& Gupta, S. K. (2020). Influences on purchase intentions of organic food consumers in an emerging economy. Journal of Asia Business Studies, 14(5), 599620. https://doi.org/10.1108/JABS-12-2019-0364

Fakhlaei, R., Selamat, J., Khatib, A., Razi, A. F. A., Sukor, R., Ahmad, S., \& Babadi, A. A. (2020). The toxic impact of honey adulteration: A review. Foods, 9(11), 1538. https://doi.org/10.3390/foods9111538

Fernandes, C. (2013). Analysis of counterfeit fashion purchase behaviour in UAE. Journal of Fashion Marketing and Management, 17(1), 85-97. https://doi.org/10.1108/13612021311305155

Fishbein, M. (1980). A theory of reasoned action: some application and implications. Nebraska Symposium on Motivation, University of Nebraska Press, 27, 65-116. Lincoln, Nebraska.

Ghansah, F. A., Owusu-Manu, D. G., Ayarkwa, J., Edwards, D. J., \& Hosseini, M.R. (2021). Assessing the level of awareness of smart building technologies (SBTs) in the developing countries. Journal of Engineering, Design and Technology. https://doi.org/10.1108/JEDT-11-2020-0465

Gupta, N., \& Panchal, P. (2009). Extent of awareness and food adulteration detection in selected food items purchased by home makers. Pakistan Journal of Nutrition, 8, 660667. DOI: 10.3923/pjn.2009.660.667

Hair, J., Black, W., Babin, B., \& Anderson, R. (2010). Multivariate Data Analysis (7th ed.). Upper Saddle River, New York: Prentice-Hall, Inc.

Hassan, H., Sade, A. B., \& Subramaniam, L. S. (2020). Purchasing functional foods to stay fit. Journal of Humanities and Applied Social Sciences, 2(1), 3-18. https://doi.org/10.1108/JHASS-11-2019-0073

Ishwar, S., Dudeja, P., Shankar, M. P., Swain, S., \& Mukherji, S. (2016). 'Jago Grahak Jago': A cross-sectional study to assess awareness about food adulteration in an urban slum. Medical Journal Armed Forces India, 74(1), 57-60.

James, M. X., Hu, Z., \& Leonce, T. E. (2019). Predictors of organic tea purchase intentions by Chinese consumers: Attitudes, subjective norms and demographic factors. Journal of Agribusiness in Developing and Emerging Economies, 9(3), 202-219. https://doi.org/10.1108/JADEE-03-2018-0038

Jin Ma, Y., Littrell, M. A., \& Niehm, L. (2012). Young female consumers' intentions toward fair trade consumption. International Journal of Retail and Distribution Management, 40(1), 41-63. https://doi.org/10.1108/09590551211193595

Kallas, Z., Alba, M. F., Casellas, K., Berges, M., Degreef, G., \& Gil, J. M. (2019). The development of short food supply chain for locally produced honey: Understanding consumers' opinions and willingness to pay in Argentina. British Food Journal. https://doi.org/10.1108/BFJ-01-2019-0070

Kamaruddin, M. Y., Joesima, H., \& Nuruddin, M. A. M. (2006). The presence of adulterated and synthetic honeys in Malaysia. Proceedings for 1st International Conference on the Medicinal Uses of Honey, USM, Kota Bharu, Kelantan.

Lim, Y. H., Lada, S., Ullah, R., \& Abdul Adis, A. A. (2020). Non-Muslim consumers' intention to purchase halal food products in Malaysia. Journal of Islamic Marketing. https://doi.org/10.1108/JIMA-06-2020-0172 
Marmaya, N., Zakaria, Z., \& Desa, M. N. (2019). Gen Y consumers' intention to purchase halal food in Malaysia: a PLS-SEM approach. Journal of Islamic Marketing, 10(3), 1003-1014. https://doi.org/10.1108/JIMA-08-2018-0136

Mohammed, A. A. (2020). What motivates consumers to purchase organic food in an emerging market? An empirical study from Saudi Arabia. British Food Journal. https://doi.org/10.1108/BFJ-07-2020-0599

Moore, J. C., Spink, J., \& Lipp, M. (2012). Development and application of a database of food ingredient fraud and economically motivated adulteration from 1980 to 2010. Journal of Food Science, 77(4), R118- R126. doi.org/10.1111/j.1750-3841.2012.02657.x

Murphy, M., Cowan, C., Henchion, M., \& O'Reilly, S. (2000). Irish consumer preferences for honey: a conjoint approach. British Food Journal, 102(8), 585-598. https://doi.org/10.1108/00070700010348424

Nasreen, S., \& Ahmed, T. (2014). Food adulteration and consumer awareness in Dhaka City, 1995-2011. Journal of Health, Population and Nutrition, 32(3): 452-464. https://www.ncbi.nlm.nih.gov/pmc/articles/PMC4221451/

Oroian, M., Paduret, S., \& Ropciuc, S. (2018). Honey adulteration detection: Voltammetric etongue verses official methods for physicochemical parameter determination. Journal of the Science of Food and Agriculture, 98(11), 4304-4311. doi.org/10.1002/jsfa.8956

Pallant, J. (2016). A step by step guide to data analysis using IBM SPSS. Berkshire, England: McGraw Hill Education.

PWC. (2017). Food fraud vulnerability assessment. Retrieved from https://www.pwc.com/gx/en/services/food-supply-integrity-services/food-fraudvulnerability-assessment.html

Rabbanee, F. K., Afroz, T., \& Naser, M. M. (2020). Are consumers loyal to genetically modified food? Evidence from Australia. British Food Journal, 123(2), 803-819. https://doi.org/10.1108/BFJ-11-2019-0832

Rekha, N. S., \& Paul, M. M. (2018). Consumer awareness regarding food adulteration and its incidence in the market. International Journal of Research in Applied, 6(10), 29-34.

Se, K. W., Wahab, R. A., Yaacob, S. N., \& Ghoshal, S. K. (2019). Detection techniques for adulterants in honey: Challenges and recent trends. Journal of Food Composition and Analysis, 80, 16-32. https://doi.org/10.1016/j.jfca.2019.04.001

Alam, S., \& Sayuti, M. N. (2011). Applying the Theory of Planned Behaviour (TPB) in halal food purchasing. International Journal of Commerce and Management, 21(1), 8-20. https://doi.org/10.1108/10569211111111676

Soares, S., Amaral, J. S., Beatriz, M. P. P. O., \& Mafra, I. (2017). A comprehensive review on the main honey authentication issues: Production and origin. Comprehensive reviews in food Science and food safety, 16(5), 1072-1100. https://doi.org/10.1111/15414337.12278

Teng, C. C., \& Wang, Y. M. (2015). Decisional factors driving organic food consumption: Generation of consumer purchase intentions. British Food Journal, 117(3), 1066-1081. https://doi.org/10.1108/BFJ-12-2013-0361-comercializar-miel-con-trazabilidaddesde-su-origen_975497

Wang, L., Wong, P. P. W., \& Alagas, N. E. (2020). Antecedents of green purchase behaviour: an examination of altruism and environmental knowledge. International Journal of Culture, Tourism and Hospitality Research, 14(1), 63-82. https://doi.org/10.1108/IJCTHR-02-2019-0034 
Xin, L., \& Seo, S. (2019). The role of consumer ethnocentrism, country image, and subjective knowledge in predicting intention to purchase imported functional foods. British Food Journal, 122(2), 448-464. https://doi.org/10.1108/BFJ-05-2019-0326

Yadav, R., \& Pathak, G. S. (2017). Determinants of Consumers' Green Purchase Behaviour in a Developing Nation: Applying and Extending the Theory of Planned Behaviour. Ecological Economics, 134, 114-122. https://doi.org/10.1016/j.ecolecon.2016.12.019

Zheng, Z., Gao, Y., Zhang, Y., \& Henneberry, S. (2017). Changing attitudes toward genetically modified foods in urban China. China Agricultural Economic Review, 9(3), 397-414. https://doi.org/10.1108/CAER-04-2017-0061

Zhou, Y., Thogersen, J., Ruan, Y., \& Huang, G. (2013). The moderating role of human values in planned behaviour: the case of Chinese consumers' intention to buy organic food. Journal of Consumer Marketing, 30(4), 335-344. https://doi.org/10.1108/JCM-022013-0482

Zhu, W., Yao, N. C., Ma, B., \& Wang, F. (2018). Consumers' risk perception, information seeking, and intention to purchase genetically modified food: An empirical study in China. British Food Journal, 120(9), 2182-2194. https://doi.org/10.1108/BFJ-11-20170622 